\title{
MANIFESTAÇÕES DA EMPATIA NA EXPERIÊNCIA DE (GAME) DESIGN INTERESPÉCIE
}

\author{
EMPATHY MANIFESTATIONS IN INTERSPECIES \\ (GAME) DESIGN EXPERIENCES
}

\author{
Fabrício Fava, PhD. \\ Pontifícia Universidade Católica de São Paulo \\ email: fabriciofava@gmail.com
}

\begin{abstract}
Design, Jogos Digitais, Empatia, Interação Animal-Computador, Interespécie
No presente trabalho são observadas formas de manifestação da empatia na experiência de (game) design interespécie. Para isso, são discutidos aspectos gerais da empatia e suas interseções com o design e os games; em seguida, são observadas algumas abordagens de game design no contexto da Interação Animal-Computador; e, por fim, são apresentadas quatro experiências de (game) design interespécie e discutidas formas de manifestação da empatia. Os resultados mostram que respostas empáticas cognitivas e emocionais como tomada de perspectiva, construção de relacionamento e pensamento reflexivo podem ser percebidas tanto durante a atividade de game design quanto por meio da observação da interação de animais com tecnologia.
\end{abstract}

Design, Games, Empathy, Animal-Computer Interaction, Interspecies In the present work are observed forms of empathy manifestations in interspecies (game) design experiences. In order to do this, general aspects of empathy and its intersections with design and games are discussed; then, some game design approaches are observed in the context of Animal-Computer Interaction; and, finally, four interspecies (game) design experiences are briefly discussed and possible ways of empathy manifestations are pointed out. The research shows that cognitive and emotional empathetic responses such as perspective-taking, relationship-building and reflective thinking can be perceived during the game design activity as well as by observing the animal-technology interaction.

\section{Introdução}

O Design passa por constantes evoluções e expansões ao longo dos anos, sejam elas sociais, culturais, interacionais, técnicas, metodológicas. Aspecto evidenciado na própria temática desta edição do Interaction Latin America, que se propõe a pensar fronteiras do Design de Interação. A mais recente transformação que temos testemunhado é a mudança de uma perspectiva de produto para uma de experiência, ou seja, de objetos de característica material para aqueles de qualidade imaterial. Isso inclui novos tipos de processos, serviços, interação, entretenimento, modos de comunicação. Nesse contexto, onde o design centra-se cada vez mais na compreensão das qualidades humanas e na busca por insights relativos à experiência do usuário, a empatia surge como um fator chave.

Atinente ao processo comunicativo, colaborativo e criativo que se desenrola nas relações entre o designer e o usuário, a empatia é usada para definir as características resultantes dessa relação. Ela é o esforço para conectar-se com as pessoas em um nível fundamental: observar/conhecer o mundo da mesma maneira que elas, compreendê-lo a partir de suas experiências e senti-lo através de suas emoções (BROWN, 2009). Vale ressaltar que o movimento em direção à empatia não se trata do designer se colocar no papel do outro, mas, apoiado em um processo dialógico, poder engajar-se com o outro a partir de suas experiências e perspectivas.

De maneira geral, empatia refere-se à emoção moral concernente ao bem-estar dos outros que facilita os relacionamentos interpessoais e influencia positivamente as pessoas a se engajarem em comportamentos pró-sociais e altruístas (MENCL \& MAY, 2009). Entre as características positivas associadas ao desenvolvimento da empatia estão a apreensão de diferentes perspectivas e experiências, a expansão da comunicação e a tendência à tomada de decisões éticas.

Tais benefícios vão além de melhorar as atitudes e motivar comportamentos mais afetivos em relação aos humanos. Pessoas empáticas demonstram, por exemplo, sentimentos mais fortes de obrigação moral para ajudar animais, plantas e a natureza como um todo (BERENGUER, 2007). Nesse 


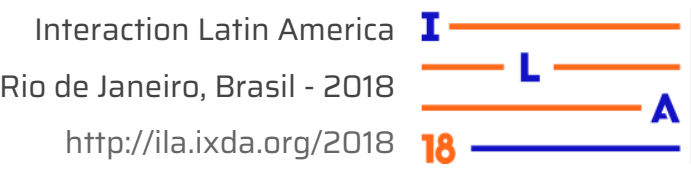

sentido, a emergência da disciplina Interação Animal-Computador (IAC) (MANCINI, 2011) parece nos colocar diante de uma nova perspectiva de expansão do Design de Interação.

Os esforços da IAC propõem a aplicação de princípios de design que posicionem o animal no centro de um processo de desenvolvimento iterativo como um legítimo usuário e contribuidor de design (MANCINI, 2013). Isso envolve reconhecer que os animais possuem a habilidade de sentir, perceber, experienciar subjetividade, mas sem olhá-los a partir de uma perspectiva essencialmente antropocêntrica. Ou seja, sem buscar, por exemplo, associar sua forma de pensar ou sentir à nossa, ou comparar se eles estão cientes do ambiente em que vivem da mesma maneira que estamos.

Promover um sentimento de empatia, no entanto, não é uma tarefa simples. Hess e Fila (2017) apontam que as experiências empáticas devem refletir-se em um nível intrínseco e as experiências imersivas mostram-se um meio relevante para isso. Característica que nos aproxima do design de games, uma vez que são bons meios de promoção de imersão para novos contextos, engajamento em narrativas e representação de papéis. A lógica dos games, auxiliada, sobretudo pela emergência da gamificação, tem tido implicações no estimulo ao desenvolvimento de distintas habilidades de aprendizagem (GEE, 2007), criativas (FAVA, 2016) e empáticas (FARBER \& SCHRIER, 2017).

Sabe-se que a atividade lúdica é também compartilhada pelos animais (FAVA, 2018) e representa uma característica de bem estar, na medida em que só ocorre em momentos nos quais eles não estão submetidos a situações de stress. O uso das tecnologias digitais para a promoção de experiências de engajamento entre pessoas e o mundo natural (WEBBER et al., 2017), sobretudo a partir do aspecto lúdico, têm se beneficiado dessas qualidades. Mas seria possível estimular a empatia por meio do design lúdico interespécie? Caso sim, como essa característica é manifestada nas relações entre humanos e animais não humanos em um contexto de (game) design?

\subsection{Metodologia}

Em busca de responder a essas questões, parte-se da premissa da perspectiva do design como uma via para a construção de novas formas de interação e comunicação interespécie e observa-se o aspecto lúdico como um elemento capaz de potencializar a empatia nessas relações. Dessa maneira, o presente trabalho discute a manifestação da empatia interespécie no contexto do (game) design a partir de uma abordagem de design centrado na experiência.

A partir de uma breve apresentação do estado da arte da empatia nos contextos do design e do jogo; e de considerações sobre a inserção do design lúdico nas pesquisas de IAC; serão apresentadas quatro experiências de (game) design interespécie e levantados insights sobre as manifestações da empatia no contexto dessas interações.

A escolha dessas experiências é resultado de uma pesquisa bibliográfica realizada em Agosto de 2018 na base de dados do Google Acadêmico. Essa pesquisa indica que a observação da empatia no contexto do design de games interespécie é rara: uma busca para os termos "animal computerinteraction", "game design" e "empathy" retornou apenas 10 trabalhos - nenhum deles em língua portuguesa. Destes, somente um dedicava-se diretamente ao tema (WEBBER et al., 2017); outros dois referiam-se a empatia como tema transversal (WESTERLAKEN \& GUALENI, 2016; PONS \& JAEN, 2017); e os demais ou mencionavam o termo empatia ou citavam estudos anteriores.

\section{Considerações sobre empatia}

Empatia é um fenômeno associado a diferentes aspectos, como: competência, habilidade, virtude intelectual, resposta comportamental, entre outras; e vem sendo observada sob as mais distintas perspectivas, como: cognitivas, emocionais, comportamentais e motoras.

Batson (2009, p.4-8) aponta oito distintas concepções resultantes das pesquisas sobre a empatia: (i) conhecer os estados internos de uma pessoa, incluindo seus pensamentos e sentimentos; (ii) adotar uma postura ou resposta neural correspondente a alguém observado; (iii) vir a sentir como outra pessoa sente; (iv) intuir ou projetar-se em uma situação vivida por outra pessoa; (v) imaginar como o outro está pensando ou sentindo; (vi) imaginar como o outro pensaria ou sentiria se estivesse no lugar de alguém; (vii) sentir angústia ao observar outra pessoa sofrendo; e (viii) sentir por outra pessoa que está sofrendo.

Essas oito distinções sobre empatia propostas por Batson podem ser sintetizadas da seguinte maneira 


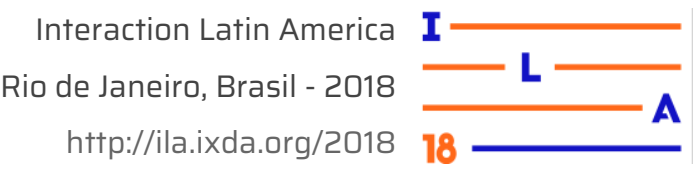

(HESS \& FILA, 2016): (i) precisão empática ou teoria da mente; (ii) mimetismo motor; (iii) contágio emocional; (iv) projeção: imaginar-se na posição de outro; (v) tomada de perspectiva: imaginar o outro; (vi) tomada de perspectiva: imaginar-se como se fosse o outro; (vii) aflição empática; e (viii) preocupação empática ou simpatia.

Outras quatro classificações acerca da empatia também podem ser encontradas no trabalho proposto por Gerdes e seus colegas (2011): (i) a capacidade para uma resposta afetiva não consciente ao outro; (ii) a capacidade cognitiva de tomar a perspectiva do outro; (iii) a habilidade de regular as emoções; e (iv) um nível de autoconsciência que permite alguma identificação temporária com o outro.

Essas percepções refletem aspectos cognitivos, emocionais e motores. Eles nos permitem entender a empatia a partir de uma resposta intelectual em imaginar/compreender os pensamentos, intenções, conhecimento e afetividade do outro; uma resposta afetiva ao estado emocional do outro; ou uma resposta motora/mimética ao movimento, postura e expressões faciais a partir da observação do outro.

Tais concepções, no entanto, conforme apontam Justin Hess e Nicholas Fila (2016), parecem limitar a compreensão da empatia a uma ação altruística, e não uma ação em si, ou seja, sem observá-las em termos comportamentais - embora a empatia seja um fator motivador para a ação, sobretudo a de ajudar ao outro (DAVIS, 1996).

Um indício em direção a essa perspectiva pode ser observada no trabalho de Decety e Jackson (2004), que identificaram a intenção de responder com compaixão como um componente central da empatia. Davis (1996) acrescenta que temos afinidades variadas para utilizar tipos distintos de empatia e que os tipos de empatia cognitiva (pontos i, iv, v e vi propostos por Batson citados anteriormente) ou afetiva (pontos ii, iii, vii e viii propostos por Batson citados anteriormente) culminam em comportamento.

A empatia, portanto, "inclui experiências afetivas e processos cognitivos que podem ser preparados automaticamente ou subconscientemente, operar isoladamente ou simultaneamente, mas tendem a ter uma relação cíclica" (HESS \& FILA, 2016, p.4). Nesse processo, as experiências afetivas compreendem aflição empática e preocupação empática, enquanto os processos cognitivos incluem tomadas de perspectiva que podem ser orientadas para si ou ao outro.

\subsection{A empatia no contexto do Design}

A mediação de relações empáticas entre designer e usuário já vem sendo explorada no contexto da Interação Humano-Computador e do Design de Interação há certo tempo. Suri (2001), por exemplo, já apontava a empatia como um fator necessário à Ergonomia para lidar com desafios e oportunidades futuras. Mattelmäki e Battarbee (2002) a exploraram no contexto do design de experiências pessoais com tecnologias interativas. Wright e McCarthy (2008), por sua vez, dedicaram-se à característica dialógica da empatia no design de experiência do usuário.

Essas pesquisas, voltadas essencialmente à esfera humana, são resultados de desafios encontrados a partir do final dos anos 1990, com uma nova demanda de design em busca da exploração de experiências, ações significativas e aspectos emocionais (MATTELMÄKI et al., 2014). Isso levou a uma necessidade de encontrar novas formas de lidar com as incertezas oriundas da inserção dessas questões. Nesse contexto, o design empático (LEONARD \& RAYPORT, 1997) surge como uma abordagem adicional às práticas ergonômicas e de pesquisas de marketing e produto.

Leonard e Rayport reconhecem que o feedback adquirido por meio de técnicas de observação, como testes de usabilidade e requisitos ergonômicos são valorosos para as ideias de projeto. A aplicação das técnicas do design empático em adição a essas práticas, no entanto, poderia oferecer benefícios para a coleta de pelo menos cinco tipos de informações: (i) gatilho de uso, (ii) interações com o ambiente do usuário, (iii) personalização, (iv) atributos intangíveis do produto e (v) necessidades de usuário não articuladas.

Os autores propuseram a combinação de métodos subjetivos e objetivos para o design realizados no contexto do usuário. Isso incluía interações criativas entre os integrantes de uma equipe multidisciplinar; curiosidade e habilidades perceptivas; inserção de um olhar aberto, sem pré-concepções no contexto do usuário. Nessa perspectiva, quanto mais próximo do usuário, maior a probabilidade de o designer chegar a ideias e soluções significativas.

O método do design empático era visto como uma ferramenta para o desenvolvimento das habilidades 


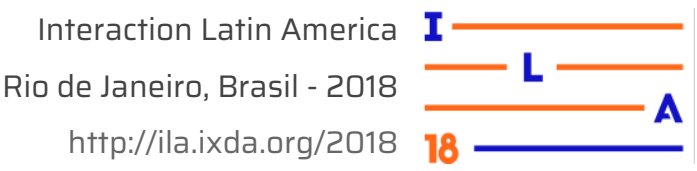

do designer em conectar-se com as pessoas e envolvia: observação, coleta de dados, reflexão e análise, brainstorm para soluções e desenvolvimento de protótipos de possíveis soluções.

Essa perspectiva do design empático desloca-se para o design centrado no usuário, sobretudo com o movimento de design participativo, a partir dos anos 2003, quando se percebe a mudança do design de produto para a interação com sistemas e serviços (MATTELMÄKI et al., 2014). Momento em que a noção de design thinking ganha emergência (BROWN \& WYATT, 2010). Abordagem essa que também tem entre os seus princípios a experimentação, colaboração, cocriação, foco no ser humano, viés holístico.

Atualmente existem diversas técnicas e atividades que se propõem a incitar a empatia no processo de design. Entre elas pode-se citar etnografia, sondas culturais (cultural probes), narrativas (como o design baseado em cenários, por exemplo), entrevistas e prototipação. A IDEO, por exemplo, uma reconhecida consultoria em design e inovação, desenvolveu uma série de cartões com recomendações técnicas e metodológicas para facilitar o processo de Design. Entre eles é possível encontrar alguns direcionados ao estabelecimento de relações empáticas com os usuários, como a entrevista. Outro exemplo pode ser encontrado na renomada escola de Design D.SCHOOL, que também propõe um guia para a atividade de Design com práticas para estimular a empatia, como entrevista e prototipação.

Ao falarmos em codesign ou design participativo estamos nos referindo também à empatia, pois suas práticas revelam a individualidade dos sujeitos. A construção da empatia é estabelecida por uma relação estética formada a partir do aprendizado das qualidades e valores do outro. Esse processo dialógico e imersivo pode demandar tempo até que o designer seja capaz de reconhecer comportamentos e estratégias que as pessoas utilizam para lidar com a complexidade do mundo. A percepção desses comportamentos é posteriormente traduzida em tendências de projeto para a geração de sistemas/serviços capazes de impactar a vida dos indivíduos. Nesse contexto, o designer aparece como uma espécie de intermediador cultural.

\subsection{A empatia no contexto dos Jogos Digitais}

Por muito tempo, os videogames estiveram comumente limitados a uma noção de puro entretenimento. Essa concepção vem se alterando e, atualmente, já se percebe a expansão de sua lógica e do interesse em aproveitar o seu potencial para a promoção de mudanças culturais e sociais nos mais diversos contextos. Entre essas transformações está a discussão de uso de games para o estímulo à empatia (BELMAN \& FLANAGAN, 2010; GREITEMEYER, 2013; DARVASI, 2016; FARBER \& SCHRIER, 2017).

O estado da arte sobre as interseções entre jogos digitais e empatia é ainda limitado. $\mathrm{O}$ trabalho mais recente nessa área parece ser o de Matthew Farber e Karen Schrier (2017), onde os autores apresentam alguns insights acerca das relações entre jogos e empatia. Apesar de acabarem levantando mais questões do que propriamente apresentando respostas para o tema, o texto serve como um bom ponto de partida para o entendimento do assunto. Nele os autores discutem cinco aspectos característicos dos games e como eles se relacionam com a empatia: (i) imersão e transporte para o mundo do jogo, (ii) agenciamento, (iii) tomada de perspectiva e identidade, (iv) relações com personagens não jogáveis e (v) conexão, comunicação e reflexão.

\section{(i) Imersão e transporte para o mundo do jogo}

Uma das características mais marcantes dos games é a sua potencialidade para a geração de experiências imersivas. Dessa maneira, o jogador é capaz de vivenciar momentos de fluxo, tendo seus sentidos e percepção transportados para o mundo do jogo. $\mathrm{O}$ envolvimento do jogador com mundos imaginários tem na narrativa uma de suas vias mais relevantes. Muitas vezes o jogador é colocado em uma posição de protagonista de ação ao controlar um avatar, por exemplo. Essa experiência ativa é capaz de estimular comportamentos e ações relacionados à empatia (MAHOOD \& HANUS, 2017).

Vale salientar que, conforme aponta Isbister (2016), essas experiências conectivas não são exclusivas de mídias com as quais o processo de interação é explícito. Elas também ocorrem, por exemplo, na relação com o cinema e a televisão. No entanto, há, na interação com os games, uma possibilidade maior de estímulo a emoções sociais e, por conseguinte, uma possível correlação do resultado dessas experiências à empatia.

\section{(ii) Agenciamento}

A sensação de que as ações e escolhas realizadas pelo jogador durante o gameplay resultam em 


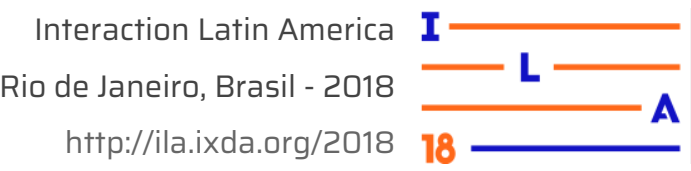

mudanças significativas no mundo do jogo é o que se pode chamar de agência (MURRAY, 2003). A possibilidade de fazer escolhas ajuda ao jogador a controlar a sua experiência de jogo e normalmente provoca um senso de livre arbítrio - embora saibamos que tais ações sejam limitadas pelo projeto de interação e programação do game. Por outro lado, ainda que o senso de agência possa ser significativo e pessoalmente relevante, "ele também pode diminuir a empatia porque o jogador não está distante o suficiente de suas escolhas" (FARBER \& SCHRIER, 2017, p. 14).

\section{(iii) Tomada de perspectiva e identidade}

A tomada de perspectiva refere-se ao ato de assumir o ponto de vista do outro, tornando possível entendê-lo melhor, ainda que não tenhamos a mesma visão ou concordemos com ela. Hofman (2000) considera a tomada de perspectiva como a forma mais avançada de empatia, pois possibilita que nos tornemos afetivamente empáticos pelo outro ainda que eles não estejam presentes. Para que isso ocorra, é preciso que estejamos abertos ao outro e, no caso da narrativa ficcional, ela deve ser imersiva, interessante e convincente (JOHNSON, 2012).

A tomada da perspectiva do personagem no contexto dos games ajuda a formar um senso de identidade e conforme aponta Darvasi (2016), o jogador torna-se mais facilmente empático ao olhar, necessidades e experiências do personagem quando ele pode vê-lo na tela. Isso pode ocorrer ao se assumir uma perspectiva em terceira pessoa, ou quando se pode intercambiar entre as perspectivas de primeira e terceira pessoa.

\section{(iv) Relações com personagens não jogáveis}

Além da identificação com os personagens controlados pelo jogador, é possível também criar vínculos com os personagens autônomos, controlados digitalmente pelo design da programação do jogo. Eles podem, por exemplo, estar integrados à experiência de gameplay sob a função de guias que auxiliam o jogador durante a jornada ou como parceiros de equipe que competem e progridem ao seu lado. O relacionamento independente com esses personagens não jogáveis é desenvolvido com o tempo e pode ser capaz de fazer com que o jogador se conecte e crie empatia por eles. Harth (2017) observou que possíveis emoções empáticas estabelecidas com tais personagens são similares ao apego emocional que se constitui com atores performando em um palco ou com os personagens de um livro. (v) Conexão, comunicação e reflexão

Farber e Schrier (2017) apontam que as relações comunicativas e interativas com outros seres humanos também podem apoiar a tomada de perspectiva, interpretação de papéis, reflexão, agência, formação de identidade e relacionamentos. Essa interação social é uma via relevante para a prática de habilidades relacionadas à empatia, ética e senso moral (BELMAN \& FLANAGAN, 2010; SCHRIER, 2015; HESS \& FILA, 2016). São diversos os fatores que podem nos ajudar a desenvolver habilidades de empatia a partir da relação com o outro como, por exemplo: tendo-o como um modelo de comportamento; engajando-nos com ele por meio do diálogo; ou nos envolvendo emocionalmente com ele.

Observando os aspectos relacionados à empatia discutidos até aqui, tanto de maneira geral quanto inserida no contexto do design e dos games, é possível perceber alguns indícios gerais de sua manifestação. A empatia sugere uma predisposição para que ocorra, mas, ao mesmo tempo em que demanda presença, há também ausência, distanciamento, uma vez que é preciso conectar-se com o outro para empatizar. Isso implica em um possível desprendimento de individualidade para um projetar em comunhão, que pode se dar de maneira afetiva ou cognitiva. Essa conexão com o outro pode ocorrer tanto pela observação quanto pela relação dialógica. Esta última, aliás, parece mais intensa, uma vez que se consolida na experiência de interação com o outro.

Nesse contexto, o design e o jogo podem ser observados como vias de emergências para 0 desenvolvimento das formas de empatia. Tanto o design quanto o game são atividades que pressupõem/estimulam o engajamento de seus atores e propiciam o mergulho imersivo em experiências e contextos novos. Essas qualidades, vistas até aqui sob o ponto do humano, indiciam um potencial de expansão perceptiva e cognitiva para um campo mais amplo de relações compreendido neste trabalho como o fenômeno da empatia interespécie.

\section{Design e jogos digitais na interação animal com a tecnologia}

As pesquisas que envolvem interação entre animais e tecnologia não são recentes (MANCINI, 2017). No entanto, a percepção de que suas abordagens de projeto não estavam focadas no design centrado no animal é levantada de maneira mais evidente apenas 


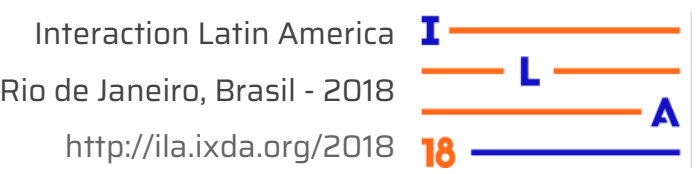

em 2011, quando Clara Mancini publica um manifesto sobre a Interação Animal-Computador (MANCINI, 2011). Nesse documento a autora descreve objetivos científicos, abordagens metodológicas, princípios éticos e esboça uma agenda científica para o desenvolvimento sistemático da IAC como uma disciplina. Seu objetivo é compreender a interação entre animais, tecnologias e elementos contextuais do ambiente em que vivem. Isso inclui a relação com pares da mesma espécie ou de espécies diferentes.

Passados sete anos desde a publicação do manifesto, as pesquisas que envolvem o tema começam a se desenvolver - embora se possa dizer que ainda encontrem-se em fases experimentais. As pesquisas referenciam-se basicamente do conhecimento da Interação Humano-Computador e começam a inserir práticas de design centrado no usuário (FRENCH et al., 2017).

Uma ideia dessas experimentações pode ser percebida na pesquisa realizada por Hirskyj-Douglas e seus colegas (2018). Após uma extensa revisão de literatura do campo, os autores identificaram e classificaram as tecnologias adotadas na IAC a partir de suas formas de uso: tangível e física; háptica e vestível; olfativa; baseada em tela; e de rastreamento. Uma síntese dessas tecnologias associadas às interfaces, espécies e objetivos propostos na bibliografia estudada pode ser observada na Tabela 1.

Os resultados dessa pesquisa apontam a promoção de experiências lúdicas como um objetivo de design recorrente. Isso pode ser justificado pelo fato de a atividade lúdica ser considerada um indicador de bem-estar animal (OLIVEIRA et al, 2010) este também um objetivo recorrente no projeto de interação animal com a tecnologia. Dentro desse contexto, o design de games torna-se uma via recorrente de experimentação.

Entre os objetivos principais desses estudos está a exploração das interações lúdicas mediadas pela tecnologia como uma via potencial de melhoria de qualidade de vida de animais. Pode-se citar, por exemplo, uma interface para a interação remota entre humanos e porcos (ALFRINK et al., 2013); um jogo interativo para o entretenimento e estímulo cognitivo de cães que passam os dias sozinhos em casa (GEURTSEN et al., 2015); e um projeto de experiências de entretenimento para elefantes (FRENCH et al., 2018).

Muitos deles envolvem também o design de interação interespécie como forma de sensibilização para a relação entre homem e animal. Entre esses projetos pode-se citar um jogo de realidade mista que permite ao dono de pequenos animais, como hamsters, jogarem com eles remotamente (CHEOK et al., 2011); um jogo para ser jogado simultaneamente por um humano e um gato

\begin{tabular}{|c|c|c|c|}
\hline Tecnologia & Interface & Espécie & Objetivo \\
\hline Tangível e física & $\begin{array}{l}\text { Interface animal-robótica } \\
\text { Brinquedos } \\
\text { Sistema de botões } \\
\text { Sistemas sonoros de toque } \\
\text { Sistema de recompensa }\end{array}$ & $\begin{array}{l}\text { Galinhas } \\
\text { Cachorros } \\
\text { Elefantes } \\
\text { Orangotangos }\end{array}$ & $\begin{array}{l}\text { Controle } \\
\text { Comunicação } \\
\text { Bem-estar } \\
\text { Saúde humana } \\
\text { Diversão }\end{array}$ \\
\hline Háptica e vestível & $\begin{array}{l}\text { Colares de biotelemetria } \\
\text { Colares GPS } \\
\text { Unidades de medida inercial (IMU) } \\
\text { Colete, botão e pratos vibrotáteis } \\
\text { Interfaces vestíveis }\end{array}$ & $\begin{array}{l}\text { Galinhas } \\
\text { Vacas } \\
\text { Grilos } \\
\text { Cachorros } \\
\text { Elefantes } \\
\text { Porcos }\end{array}$ & $\begin{array}{l}\text { Controle } \\
\text { Comunicação } \\
\text { Trabalho animal } \\
\text { Serviço animal }\end{array}$ \\
\hline Olfativa & $\begin{array}{l}\text { Alimento } \\
\text { Sensores de pressão } \\
\text { Interface de cheiro }\end{array}$ & $\begin{array}{l}\text { Cervo } \\
\text { Cachorro }\end{array}$ & $\begin{array}{l}\text { Controle } \\
\text { Comunicação } \\
\text { Trabalho animal }\end{array}$ \\
\hline Baseada em tela & $\begin{array}{l}\text { Paredes interativas } \\
\text { Tablets } \\
\text { Telas sensíveis ao toque } \\
\text { Telas de TV }\end{array}$ & $\begin{array}{l}\text { Gatos } \\
\text { Cachorros } \\
\text { Orangotangos } \\
\text { Porcos }\end{array}$ & $\begin{array}{l}\text { Bem-estar } \\
\text { Saúde humana } \\
\text { Diversão } \\
\text { Serviço animal } \\
\text { Trabalho animal }\end{array}$ \\
\hline De rastreamento & $\begin{array}{l}\text { Sensores de profundidade } \\
\text { Câmeras RGB } \\
\text { Câmeras termais }\end{array}$ & $\begin{array}{l}\text { Gatos } \\
\text { Galinhas } \\
\text { Cachorros } \\
\text { Girafas } \\
\text { Cavalos } \\
\text { Ratos } \\
\text { Orangotangos } \\
\text { Porcos }\end{array}$ & $\begin{array}{l}\text { Bem-estar } \\
\text { Monitoramento } \\
\text { Diversão }\end{array}$ \\
\hline
\end{tabular}

TABELA 1. Classificacões de tecnologias interativas na Interacão Animal-Computador (adaptado de HIRSKYJ- 


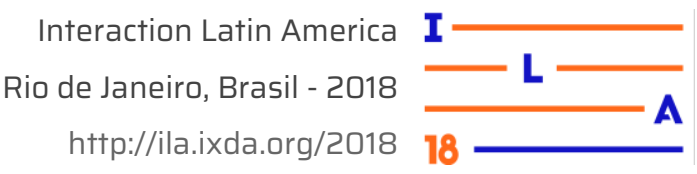

(WESTERLAKEN \& GUALENI, 2014); e a exploração de percepções humanas sobre interações lúdicas de cães utilizando tablets (BASKIN \& ZAMANSKY, 2015).

Na seção a seguir serão discutidas quatro experiências de (game) design no contexto da IAC: um estudo com visitantes de um zoológico realizado por Sarah Weber e seus colegas (2017); uma atividade experimental de game design com crianças conduzida por Patricia Pons e Javier Jaen (2017); uma pesquisa exploratória de game design com dois orangotangos liderada por Hannah Wirman (2014); e um exercício exploratório de (game) design envolvendo uma colônia de formigas comandado por Michelle Westerlaken e Stefano Gualeni (2016).

As discussões desses projetos permitirão a observação - tanto do ponto de vista de designers quanto de usuários - de como formas e características da empatia possivelmente se manifestam durante atividades de game design interespécie.

\section{Revelações da empatia no contexto da experiência de (game) design interespécie}

Em um estudo conduzido no Zoológico de Melbourne, Austrália, Sarah Webber e seus colegas (2017) projetaram e analisaram uma instalação interativa para seis orangotangos com o objetivo de compreender as formas de empatia experienciadas pelos seres humanos ao observar os animais interagindo com a tecnologia. Para entender o papel da empatia no contexto do zoológico a equipe de pesquisadores considerou aspectos de empatia cognitiva (imaginar como os animais poderiam sentir e pensar) e emocional (respostas afetivas ao observar o estado dos animais), além da percepção de similaridades entre animais e humanos.

Foram realizados encontros e workshops com funcionários e tratadores a partir dos quais a equipe identificou três estratégias específicas para evocar respostas empáticas: (i) permitir aos visitantes observarem o comportamento natural dos animais de maneira próxima; (ii) tornar visível aos visitantes as capacidades cognitivas dos orangotangos; e (iii) permitir aos visitantes observar diferenças entre comportamentos e preferências individuais dos animais.

A partir dessas estratégias, foram desenvolvidas quatro aplicações que utilizavam um sensor
Microsoft Kinect e um projetor para criar uma interface touchscreen projetada no chão do recinto dos orangotangos. Duas delas de interação mais simples, sendo uma de projetação de luzes coloridas (Fig. 1) e outra que projetava gráficos visuais que desapareciam quando tocados pelo animal; e outras duas mais complexas, sendo uma de pintura, que simulava a experiência de um pincel em uma tela e outra contendo uma galeria de seis imagens e vídeos que eram reproduzidos com a interação do animal.

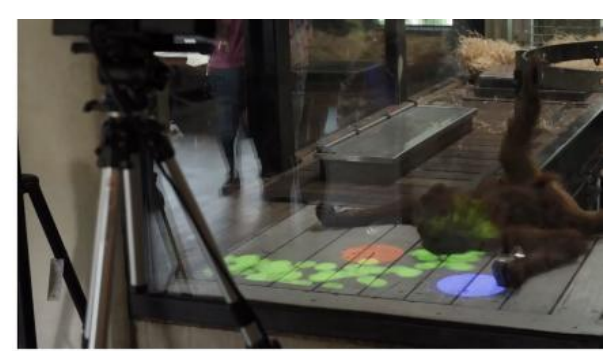

Figura 1. Orangotango interagindo com uma das aplicações.

O sistema foi instalado e ativado por períodos de duas a três horas durante quatro semanas. Durante o tempo em que o sistema ficou ativo a equipe de pesquisadores realizou entrevistas semi-estruturadas com 25 visitantes para discutir aspectos da interação, como, por exemplo: o que eles haviam aprendido com a experiência, como a percepção deles em relação aos animais foi afetada e quais suas impressões sobre a instalação. Os autores perceberam a manifestação de formas de empatia em nível cognitivo, emocional e motor.

A forma de empatia cognitiva revelou-se a partir de quatro aspectos gerais. Os visitantes refletiram sobre (i) as intenções do animal em relação à instalação e perceberam que os orangotangos abordavam e interagiam com o sistema sem a mediação de um humano: "eles não eram recompensados por interagirem com a tecnologia. Então, nesse sentido, é uma coisa boa, pois se trata de uma exploração livre e não um tipo de treinamento para utilizá-la".

Os entrevistados refletiram também sobre o que consideraram (ii) desejos dos animais, por interagirem com a instalação de formas potencialmente diferente dos humanos: "o que é mais interessante é que eles estão usando as costas da mão para brincar com os padrões e ela está obviamente intrigada"; "eles parecem se divertir".

Outro aspecto sobre o qual os seres humanos refletiram foi quanto ao (iii) aprendizado e inteligência. Suas percepções foram impactadas pela 


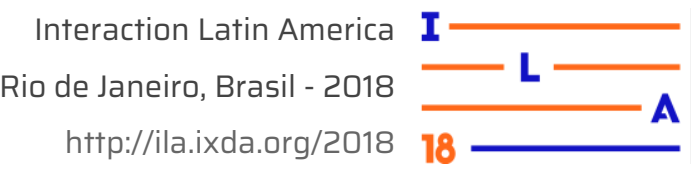

experiência e promoveu neles mudanças de ponto de vista em relação aos animais: "eles podem fazer muito mais do que pensei, eu não havia pensado que eles podiam fazer coisas com tecnologia". A percepção do rápido aprendizado na interação com o sistema também indicou um engajamento reflexivo com os animais e um particular interesse em seu estado intrínseco: "o desafio do programa é tentar criar coisas diferentes, eles vão ter que ficar sempre revisitando isso, porque eu acho que com a maioria dos animais, se eles puderem resolver certos problemas eles vão tornar-se aptos para chegar a um próximo nível e ao chegar lá eles podem ficar entediados".

Foram ponderadas, ainda, percepções sobre (iv) similaridades entre orangotangos e humanos. Este, aliás, é um aspecto que desempenha um papel importante para a empatia. Estudos têm mostrado, por exemplo, que as pessoas criam empatias por animais ao reconhecer neles características próprias do humano (BUTTERFIELD et al., 2012).

Respostas relativas à experimentação da empatia emocional também se mostraram marcantes: "eu estou meio que apaixonado por eles agora. Então, qualquer coisa que pode ajudá-los e beneficiá-los e tornar suas vidas melhores, eu acho que é fascinante".

A visibilidade e natureza dinâmica das interações também resultaram em aspectos concernentes à empatia motora. Isso se mostra, sobretudo, na percepção de movimentos dos orangotangos que pareciam intencionais: "eu vi dois deles acertando os pontos por um tempo e foi bem impressionante"; "ela está tentando identificar os padrões".

Os resultados desse projeto demonstram algumas das possibilidades de evocar a empatia interespécie por meio do design de interação sob o ponto de vista da observação da interação. O ato de observar animais enquanto eles interagem com a tecnologia pode ser um meio de provocar tomadas de perspectiva e formas de identidade capazes de estabelecer o pensamento reflexivo e diferentes formas de conexão com animais.

Patricia Pons e Javier Jaen (2017) realizaram uma pesquisa que nos permite observar essas manifestações no contexto da atividade de design. Os autores conduziram um experimento onde crianças de 5 a 13 anos pacientes de um hospital na Espanha assumiam o papel de game designers para criar jogos interespécie entre humanos e animais.
Entre os objetivos do estudo estava analisar como as crianças percebiam os animais, suas habilidades e a participação deles no jogo.

As crianças trabalharam individualmente com o pesquisador e deveriam criar cenários para dois jogos, sendo cada um para um animal diferente. $\mathrm{O}$ método de pesquisa envolveu a aplicação de um préquestionário (para entender o conhecimento e $\mathrm{o}$ sentimento da criança sobre o animal antes de projetar o jogo), um pós-questionário (para, entre outros objetivos, estimular a criança a refletir sobre o seu design e pensar sobre como o animal desfrutaria ou perceberia o jogo), e uma entrevista semiestruturada realizada durante o procedimento (para que o pesquisador pudesse compreender o jogo e guiar o processo de design).

Os resultados mostraram que muitas das soluções centravam-se no aspecto humano, não considerando as implicações do jogo para o animal. Por outro lado, elas eram mostraram-se capazes de relacionar características físicas do animal à tecnologia e dinâmica do game evitando, por exemplo, o uso de tablets e celulares, pois o formato das patas poderia não permiti-los interagir.

Apesar de ter os animais como foco de projeto, a ausência deles na atividade de design fez com que os resultados mostrassem limitados e condicionados pelo conhecimento prévio das crianças tanto em relação às espécies quanto ao uso da tecnologia. Apesar disso, percebeu-se que a experiência foi importante para gerar interesse e impactar positivamente sua opinião sobre os animais. Ao final do processo, elas demonstraram interesse em conhecer mais sobre os animais, sobretudo os selvagens. Elas também consideraram o jogo como uma ferramenta para aumentar habilidades dos animais, como velocidade, destreza e desenvolvimento do olfato. Percepções que ratificam o potencial dos games para o aprendizado e indicia, através do estimulo à reflexão e construção de relacionamento, uma possível qualidade para sensibilização à empatia.

Em outro projeto, Hannah Wirman (2014) conduziu uma pesquisa de game design exploratória com dois orangotangos em um centro de resgate e reabilitação na Indonésia. A pesquisadora inseriu tecnologias computacionais, particularmente telas sensíveis ao toque e experimentou distintos games nos quais os orangotangos poderiam realizar um conjunto de interações simples como mover objetos, fazer itens 


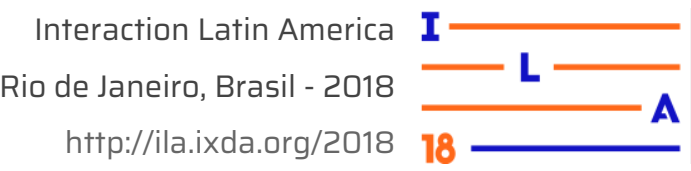

desaparecer ao tocá-los, desenhar, selecionar e assistir a vídeos. Entre os objetivos do estudo estavam a melhoria da qualidade de vida de orangotangos em cativeiro e a discussão sobre como o jogo pode ser usado como meio de facilitação da interação interespécie.

Apesar de similaridades físicas entre orangotangos e humanos, como a estrutura da mão, por exemplo, indicarem a possibilidade de sucesso na aplicação de sistemas para o enriquecimento de experiências de primatas, a experiência de Wirman revelou limitações de tal pré-concepção em pelo menos quatro aspectos interacionais: (i) mecanismos de entrada, os games não foram projetados para responder a interação usada pelos animais, como a palma das mãos, pulso, lambidas, varetas, pernas, pés e força aplicada; (ii) ângulo de visão, os orangotangos interagiam perto ou longe demais (Fig. 2), de cabeça para baixo, em cima da tela, estavam geralmente dispersos interrompendo e retomando a interação; (iii) software/hardware, as telas eram lambidas, tocadas e, frequentemente, destruídas; (iv) práticas contínuas de diversão, a interação com a tecnologia estava sempre competindo com outras formas de brincadeira e, de maneira geral, não se podia determinar quando uma brincadeira começava e outra terminava.

Essas são percepções resultantes de uma experiência dialógica. A imersão nesses ambientes de incerteza, no entanto, demanda uma postura baseada na observação, iteração e mente aberta para a aceitação de experiências diferentes. $O$ pesquisador precisa estar preparado para lidar com as frustrações desse processo: "algumas vezes, eu assumo, eu tentei ensiná-los [os orangotangos] a ser algo que eles não poderiam ser. Isso ocasionalmente levou a sentimentos de grande incompetência, os quais eu aprendi pouco a pouco a deixar passar". (2014, p. 112). A pesquisadora complementa: "se eu tivesse pegado a rota de ensinar os primatas a usar e jogar 'corretamente' os jogos que criei, isso teria sido um passo atrás do meu entendimento de jogo" (2014, p. 113).

Essas transformações regidas por abordagens produzidas pelo design estiveram no centro de um projeto desenvolvido por Michelle Westerlaken e Stefano Gualeni (2016). Os autores propuseram um exercício exploratório de (game) design envolvendo uma colônia de formigas que teve como objetivo expandir o consentimento moral e repensar criticamente nossas relações em relação aos animais.

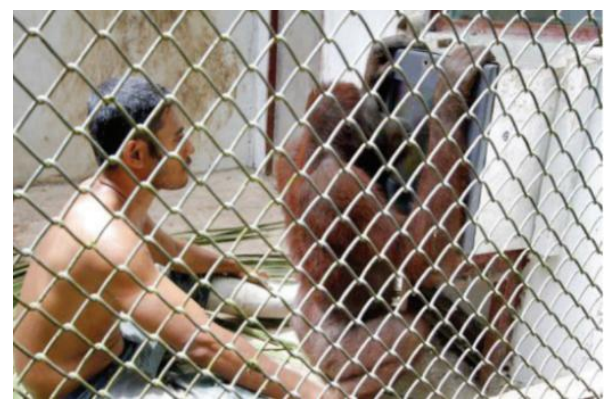

Figura 2. Orangotango interagindo bem próximo a tela sendo observado por seu cuidador.

Na primeira fase do projeto a designer Michelle Westerlaken adquiriu uma colônia de formigas e a manteve em seu ambiente de trabalho pelo período de três meses. Durante esse tempo, Westerlaken realizou observações diárias, buscou informações sobre os animais em livros, artigos e documentários e fez pequenas intervenções no arranjo da colônia para ver como as formigas reagiriam. Até que um dia elas encontraram uma pequena brecha entre as placas de seu recinto e traçaram uma rota de fuga.

Esses acontecimentos inesperados são característicos do processo fundamentalmente exploratório do design (BROWN, 2009) e o designer precisa ter a sensibilidade de perceber possíveis tendências de projeto provenientes desses episódios, como aconteceu com Westerlaken. A partir dessa percepção, o projeto tomou um rumo que se tornou possível pela relação empática que Westerlaken estabeleceu com as formigas.

Inspirada por esse comportamento foi promovida uma atividade provocativa e especulativa onde 16 alunos de design de interação e games de uma universidade sueca projetaram cinco protótipos de scape rooms (Fig. 3) para que as formigas pudessem potencialmente jogar.

Após desenvolverem os protótipos, os alunos responderam a um questionário comentando sobre as implicações de projetar cenários de interação para formigas. Pôde-se perceber que a atividade mudou a sua forma como eles observam as formigas: "foi muito interessante projetar para algo sobre o qual eu não tinha a menor ideia. Eu me sinto mais perto das formigas", "acho que nós a vemos como animais muito mais inteligentes agora".

Esses relatos críticos mostram que, por meio do game design, é possível levantar questões relacionadas à condição humana, como, por exemplo, elos de comunicação, constituição de relacionamento, expansão cognitiva, visão sistêmica, 


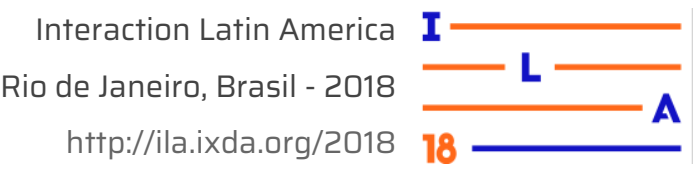

amplitude de desenvolvimento de interações concomitantes em um ambiente, potencialização de interações em multiplataformas. Relações estas que se constroem a partir do envolvimento do outro na atividade criativa.

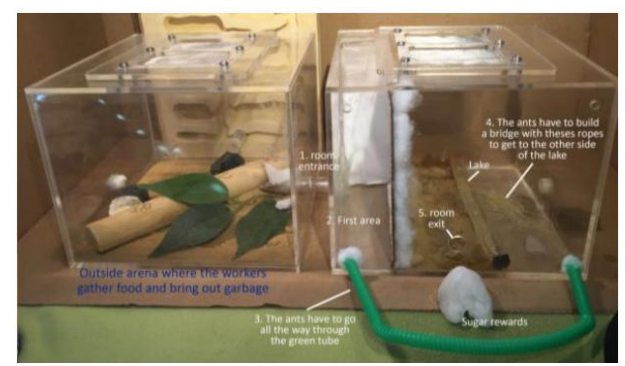

Figura 3. Um dos protótipos de scape room projetado pelos alunos: as formigas entram em uma pequena câmara na parte esquerda da caixa, em seguida têm que atravessar o tubo verde para entrar em uma área maior e escapar da caixa depois de cruzar um pequeno lago construindo uma ponte usando pedaços de cordas.

Por fim, os pesquisadores realizaram uma experiência de playtest com os protótipos. Durante cinco semanas, eles observaram as formigas interagindo com cada um deles- elas conseguiram escapar de três deles. A experiência foi transmitida online com o objetivo de gerar conversas e reflexões sobre as ideias incitadas pelo projeto. Essa situação estimulou diversas discussões online e provocou distintos graus de sensibilidade sobre como as pessoas percebiam a experiência e ao assistir a interação das formigas com os protótipos. Enquanto alguns se mostravam engajados com o projeto, outros discutiam aspectos éticos da experiência: "vocês prenderam algumas formigas e ficam assistindo enquanto elas lutam para voltar para a vida normal/natureza".

De maneira geral, a pesquisa revelou que a prática do design como forma de pensar multiespécies permitiu, "por meio de situações inesperadas, estimular novos pensamentos, pontos de vista alternativos e formas de envolvimento não vivenciadas previamente". E as formigas "agindo, escapando, respondendo e se apropriando de artefatos de maneira inesperada", influenciaram, ativamente, a maneira na qual essas transformações ocorreram e no modo como o projeto evoluiu.

\section{Considerações finais}

Neste trabalho foi investigado como a empatia pode possivelmente emergir de atividades de game design interespécie. Foram observadas quatro distintas experiências a partir das quais características relacionadas à empatia foram manifestadas tanto por meio da observação de interações entre animais e tecnologia quanto por meio da perspectiva do designer resultante de suas interações com animais não humanos. As discussões mostraram que $o$ design e os games possuem qualidades gerais e especificas capazes de promover o desenvolvimento da empatia para além de uma perspectiva humana. A relação empática com animais não humanos pode ocorrer tanto indiretamente, por meio de uma experiência de observação, quanto diretamente, a partir de uma experiência imersiva em uma interação dialógica e colaborativa com animais.

O desenvolvimento de habilidades empáticas como experiências imersivas, tomada de perspectiva, pensamento reflexivo e construção de relacionamento pode nos tornar mais abertos à percepção de novas formas de consciência animal e acesso a novos mundos fenomenológicos. Isso significa perceber os animais a partir de suas individualidades biológicas. Perspectiva esta que, possivelmente, trará influências positivas também para a expansão da consciência humana, na medida em que torna possível que novas formas de relacionamentos emirjam.

Em uma perspectiva ecológica para a IAC é preciso ter em mente que o animal está conectado a um espaço próprio e que a inserção humana nesse contexto evidenciará algumas limitações do tradicional design centrado no usuário. Não é possível, por exemplo, apresentar as instruções do jogo ao animal ou questioná-lo sobre as suas impressões em relação ao design de interação como podemos fazer ao conduzir seções de design participativo e entrevistas com humanos.

Esse cenário complexo, incerto, o qual apresenta uma diversidade de fenômenos inesperados, é, na verdade, o espaço do design. É nesse ambiente que o designer atua para reestruturar teorias, estratégias de ação, formas de conhecimento. Contexto que se mostra pertinente para a exploração e expansão das possibilidades de atuação do design de interação e de games. Nesse sentido, a concepção de Design, que já vem migrando do design de produto para o design de soluções imateriais, parece estar diante de um novo desafio: o de expandir sua compreensão comumente voltada ao humano para a apreensão de qualidades não humanas. Contexto no qual a empatia aparenta, mais uma vez, vir a ser uma via pertinente de exploração e expansão. 


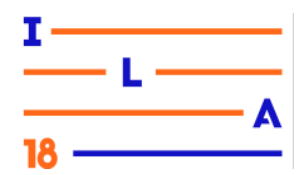

\section{Referências Bibliográficas}

ALFRINK, K.; van PEER, I.; LAGERWEIJ, H.; DRIESSEN, C.; BRACKE, M.; COPIER, M. Pig chase. Playing with Pigs Project, 2013. BASKIN, S.; ZAMANSKY, A. The Player Is Chewing the Tablet! In Proceedings of the CHI PLAY '15, London, UK, 5-7 October 2015: 463468, 2015.

BATSON, D. These things called empathy: Eight related but distinct phenomena. In The social neuroscience of empathy, Jean Decety and William Ickes (eds.). MIT Press, Cambridge, 3-15, 2009.

BELMAN, J.; FLANAGAN, M. Designing games to foster empathy. Cognitive Technology, 14 (2), 5$15,2010$.

BERENGUER, $\mathrm{J}$. The effect of empathy in proenvironmental attitudes and behaviors. Environment and Behavior, 39(2), 269-283, 2007.

BROWN, T. Change by design: how design thinking transforms organizations and inspires innovation. New York: Harper Collings, 2009.

BROWN, T.; WYATT, J. Design thinking and social innovation. Stanford Social Review, 2010.

BUTTERFIELD, M.; HILL, S.; LORD, C. Mangy mutt or furry friend? Anthropomorphism promotes animal welfare. Journal of Experimental Social Psychology 48 (4): 957-960, 2012.

CHEOK, A. et al. Metazoa ludens: mixed-reality interaction and play for small pets and humans. Systems, Man and Cybernetics, Part A: Systems and Humans, IEEE Transactions on 41.5: 876-891, 2011.

DARVASI, P. Empathy, perspective and complicity: How digital games can support peace education and conflict resolution. UNESCO MGIEP Working Paper, 2016.

DAVIS, M. Empathy: A social psychological approach. Boulder, CO: Westview Press, 1996.

DECETY, J.; JACKSON, P. The functional architecture of human empathy. Behavioral and Cognitive Neuroscience Reviews, 3(2), 71-100, 2004.
FABER, M.; SCHRIER, K. The limits and strengths of using digital games as "empathy machines”. UNESCO MGIEP, 2017.

FAVA, F. Fluke: repensando a gamificação para a aprendizagem criativa. Doctoral Dissertation. Catholic University of São Paulo, 2018.

FAVA, F. A emergência da gamificação na cultura do jogo. In: Santaella, L. Nesteriuk, S. \& Fava, F. (Orgs.) Gamificação em Debate. Blucher: São Paulo, 2018.

FRENCH, F.; MANCINI, C.; SHARP, H. Exploring Research through Design in AnimalComputer Interaction. In: Proc. Fourth International Conference on Animal-Computer Interaction, ACI2017, 21-23 Nov 2017, Milton Keynes, United Kingdom, ACM Digital Library, 2017.

FRENCH, F.; MANCINI, C.; SHARP, H. High tech cognitive and acoustic enrichment for captive elephants. J. Neurosci. Methods, 300, 173-183, 2018.

GEE, J. What video games have to teach us about learning and literacy. New York: Palgrave Macmillan, 2007.

GERDES, K.; SEGAL, E.; JACKSON, K; MULLINS, J. Teaching empathy: A framework rooted in social cognitive neuroscience and social justice. Journal of Social Work Education, 47, 109131, 2011.

GEURTSEN, A.; LAMERS, M.H.; SCHAAF, M.J.M. Interactive digital gameplay can lower stress hormone levels in home alone dogs: a case for animal welfare informatics. In 14th International Conference on Entertainment Computing (ICEC 2015) Switzerland, 9353, pp. 238-251, 2015.

GREITEMEYER, T. Playing video games cooperatively increases empathic concern. Social Psychology, 44 (6), 408-413, 2013.

HARTH, J. Empathy with non-player characters? An empirical approach to the foundations of human/non-human relationships. Journal of Virtual Worlds Research, 10 (2): 1-25, 2017.

HESS, J.; FILA, N. The development and growth of empathy among engineering students. ASEE's 


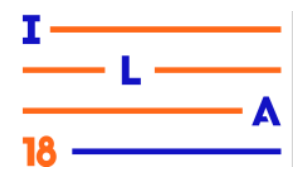

123rd Annual Conference \& Exposition, New Orleans, LA, June 26-29, 2016.

HIRSKYJ-DOUGLAS, I.; PONS, P.; READ, J.; JAEN, J. Seven Years after the Manifesto: Literature Review and Research Directions for Technologies in Animal Computer Interaction. Multimodal Technologies and Interact, 2 30, 2018.

HOFFMAN, M. Empathy and moral development: Implications for caring and justice. Cambridge, UK: Cambridge University Press, 2000.

ISBISTER, K. How games move us: Emotion by design. Cambridge, MA: MIT Press, 2016.

JOHNSON, D. Transportation into a story increases empathy, prosocial behavior, and perceptual bias toward fearful expressions. Personality and Individual Differences, 52 (2), 150155, 2012. doi:10.1016/j.paid.2011.10.005

LEONARD, D.; RAYPORT, J. Spark innovation through empathic design. Harvard Business Review, nov-dec, 1997.

MAHOOD, C.; HANUS, M. Role-playing video games and emotion: how transportation into the narrative mediates the relationship between immoral actions and feelings of guilt. Psychology of Popular Media Culture, 6(1), 61-73, 2017.

MATTELMÄKI, T.; BATTARBEE, K. Empathy probes. In Proc. Participatory Design Conference 2002, CPSR Palo Alto 266-271, 2002.

MANCINI, C. Animal-computer interaction (ACI): a manifesto. Interactions, 18 (4): 69-73, 2011.

MANCINI, C. Animal-computer interaction (ACI): changing perspective on HCI, participation and sustainability. CHI 2013 Extended Abstracts, 2013.

MANCINI, C. Como o design de software pode suportar o surgimento de interação entre animais e computadores. Revista iMasters, 23: 60-64, 2017.

MATTELMÄKI, T.; VAAJAKALLIO, K.; KOSKINEN, I. What happened to empathic design? Design Issues, 30 (1): p.67-77, 2014.

MENCL, J.; MAY, D. The effects of proximity and empathy on ethical decision-making: An exploratory investigation. Journal of Business Ethics, 85(2), 201-226, 2009.

MURRAY, J. Hamlet no holodeck: o futuro da narrativa no ciberespaço. São Paulo: UNESP, 2003.

OLIVEIRA, A., ROSSI, A., SILVA, L., LAU, M. \& BARRETO, R. Play behaviour in nonhuman animals and the animal welfare issue. $J$ Ethol 28:1-5, 2010.

PONS, P.; JAÉN, J. Designing interspecies playful interactions: studying children perceptions of games with animals. Proceedings of The Fourth International Congress on Animal Computer Interaction, 2017.

SCHRIER, K. EPIC: A framework for using video games in ethics education. Journal of Moral Education, 44 (4), 393-424, 2015.

SURI, J. The next 50 years: Future challenges and opportunities for empathy in our science. Ergonomics 44, 14, 1278-1289, 2001.

WEBBER, S.; CARTER, M.; SHERWEN, S.; SMITH, W.; JOUKHADAR, Z.; VETERE, F. Kinecting with orangutans: zoo visitors' empathetic responses to animals' use of interactive technology. In Proceedings of the CHI 2017, Brisbane, Australia, 28 November-1 December 2017: 6075-6088, 2017.

WESTERLAKEN, M.; GUALENI, S. Felino: the philosophical practice of making an interspecies videogame. Proceedings of the Philosophy of Computer Games. Istanbul, November 13-15, 2014.

\section{WESTERLAKEN, M.; GUALENI, S. Situated} knowledges through game design: a transformative exercise with ants. The Philosophy of Computer Games Conference, Malta, 2016.

WIRMAN, H. Games for/with strangers-captive orangutan (pongo pygmaeus) touch screen play. Antennae, 30: 105-115, 2014.

WISEMAN, T. A concept analysis of empathy. Journal of Advanced Nursing, 23 (6), 1162, 1996.

WRIGHT, P.; MCCARTHY, J. Empathy and experience in HCI. CHI 2008 Proceedings.

Florence, Italy, Abril 5-10, 2008. 